\title{
CARACTERIZAÇÃO E ESTUDO DAS PROPRIEDADES MECÂNICAS DE UMA JUNTA SOLDADA*
}

\author{
Willy Ank de Morais ${ }^{1}$ \\ Claudio Pereira Diogo ${ }^{2}$ \\ Alexandre Jusis Blanco ${ }^{3}$ \\ Mauricio Andrade Nunes ${ }^{4}$ \\ Jordan Souza Higa ${ }^{5}$
}

\section{Resumo}

Para se determinar as propriedades mecânicas de uma junta soldada torna-se necessário conhecer as propriedades mecânicas do metal de adição decorrente de um processo de soldagem. $O$ objetivo desse trabalho foi verificar as propriedades mecânicas de uma solda MAG elaborando e qualificando um procedimento de soldagem. Para isso foi utilizado quatro ensaios mecânicos: tração, macrográfia, micrografia e dureza. Foi estipulado o limite de escoamento, de ruptura, o alongamento e a estricção; macrográfico, determinou-se, a olho nu, a zona fundida, a zona de ligação, a zona termicamente afetada e o metal de base; micrográfico, tração, definiu-se os componentes microestruturais da solda e do metal de base; dureza e foi estabelecida a tenacidade da solda e do metal de base.

Palavras-chave: Soldagem; Metalografia; Dureza; Ensaio; Aço.

\section{CHARACTERIZATION AND STUDY OF THE MECHANICAL PROPERTIES OF A WELDED JOINT}

\section{Abstract}

To determine the mechanical properties of a welded joint becomes necessary to know the mechanical properties of filler metals arising from a welding process. The objective of this work is to check the mechanical properties of a weld MAG developing and qualifying a welding procedure. For this we will use four mechanical tests: traction, determines the yield, of rupture, elongation and contraction; macrográfico, determine, to the naked eye, the molten zone, the zone, the zone thermally affected zone and the base metal; micrográfico, determines the microstructural components of weld and base metal; hardness, the tenacity of the weld and base metal.

Keywords: Welding; Metallography; Hardness; Test; Steel.

1 Mestre em Engenharia Metalúrgica e de Materiais pela PUC-Rio, graduação em Engenharia Metalúrgica UFOP, técnico em Metalurgia pela ETFOP. Professor Adjunto da Faculdade de Engenharia da UNISANTA. Santos, SP, Brasil.

2 Bacharelando em Engenharia de Produção pela UNIMONTE. Santos, SP, Brasil.

3 Mestrando, Eng. ${ }^{\circ}$ Mecânico, Prof. Física Anglo e Centro de Paula Souza. UNISANTA, Santos, SP, Brasil.

4 Mestrando, Eng. ${ }^{\circ}$ Químico, Prof. Faculdade de Engenharia da UNISANTA, Santos, SP, Brasil.

5 Mestrando, Eng. ${ }^{\circ}$ Químico, Prof. Faculdade de Engenharia da UNISANTA, Santos, SP, Brasil. 


\section{INTRODUÇÃO}

A soldagem é uma técnica de construção, feita de várias formas e aplicando vários métodos. Visa obter peças contínuas de metais e/ou ligas [1] é o mais importante processo industrial de fabricação de peças metálicas. Processos de soldagem e processos afins são também utilizados na recuperação de peças desgastadas, para a aplicação de revestimentos de características especiais sobre superfícies metálicas e para corte.

O sucesso da soldagem está associado a diversos fatores e, em particular, com a sua relativa simplicidade e flexibilidade operacional. Por outro lado, apesar desta simplicidade, não se pode esquecer que a soldagem pode ser muitas vezes um processo "traumático" para o material, envolvendo, em geral, a aplicação de uma elevada densidade de energia em um pequeno volume do material, o que pode levar a importantes alterações estruturais [1,2] e de propriedades $[1,4]$ dentro e próximo da região da solda.

O desconhecimento ou a simples desconsideração das implicações desta característica fundamental pode resultar em problemas inesperados e, em alguns casos, graves. Estes problemas podem se refletir tanto em atrasos na fabricação ou em gastos inesperados, quando o problema é prontamente detectado, ou mesmo em perdas materiais e, eventualmente, de vidas, quando o problema é levado às suas últimas consequências.

Para se determinar as propriedades mecânicas de uma junta soldada, se torna necessário conhecer as propriedades mecânicas do metal de adição decorrente de um processo de soldagem [5]. Todo o processo de união de metais, através de componentes mecânico ou componentes estruturais através do processo de soldagem tem que ser avaliado para a verificação e comprovação da integridade do novo componente $[1,2,4]$.

\section{MATERIAIS E MÉTODOS}

\subsection{Método de Soldagem}

O método de soldagem utilizado foi GMAW (Gas Metal Arc. Welding) ou MAG (Metal Active Gas), que realiza a união de materiais metálicos pelo seu aquecimento e fusão localizados através de um arco elétrico estabelecido entre um eletrodo metálico não revestido e maciço na forma de fio [6], conforme ilustrado na Figura 1.

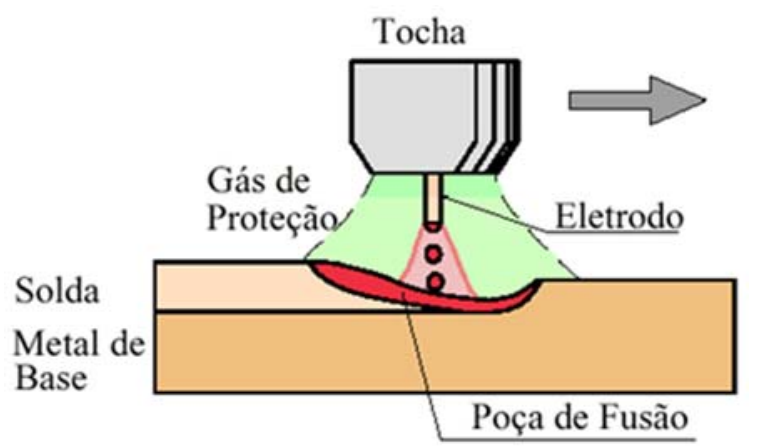

Figura 1. Esquema do processo de soldagem MAG (GMAW).

Para o procedimento de soldagem foi utilizada a pistola para soldagem GMAW que possui um contato elétrico deslizante (bico de contato) para transmitir a corrente ao 
arame, orifícios para a passagem de gás de proteção e bocal para dirigir o fluxo de gás à região do arco e da poça de fusão. Para a soldagem semiautomática, ela ainda possui um interruptor para o acionamento da corrente de soldagem, da alimentação de arame e do fluxo de gás de proteção.

\subsection{Sistema de Alimentação}

O sistema de alimentação é composto de um motor, um sistema de controle de sua velocidade e um conjunto de roletes responsável pela impulsão do arame. Em comparação com a soldagem com eletrodos revestidos, a soldagem GMAW é relativamente mais simples quanto à sua técnica de execução pois a alimentação de metal de adição é feita pelo equipamento e a quantidade de escória gerada é mínima. Por outro lado, este processo é mais complicado em termos da seleção e ajuste de seus parâmetros, devido ao seu maior número de variáveis e a forte interrelação entre elas.

A fonte de energia mais usada é do tipo tensão constante regulável com alimentação de arame a velocidade constante. Este tipo de sistema permite o controle automático do controle do arco diretamente através de variações da corrente de soldagem. Sistemas alternativos, com fontes com saída de corrente constante, necessitam de sistemas especiais para controlar o comprimento do arco.

\subsection{Confecção dos Corpos de Prova}

O material empregado nos corpos de prova (CPs) foi o aço SAE J403 1020. Os CPs para o ensaio de tração foram usinados em fresadora horizontal conforme as dimensões ilustradas na Figura 2. Estes corpos de prova foram seccionados em três partes $(A, B$ e $C)$ para serem analisados por metalografia e para terem suas durezas medidas.

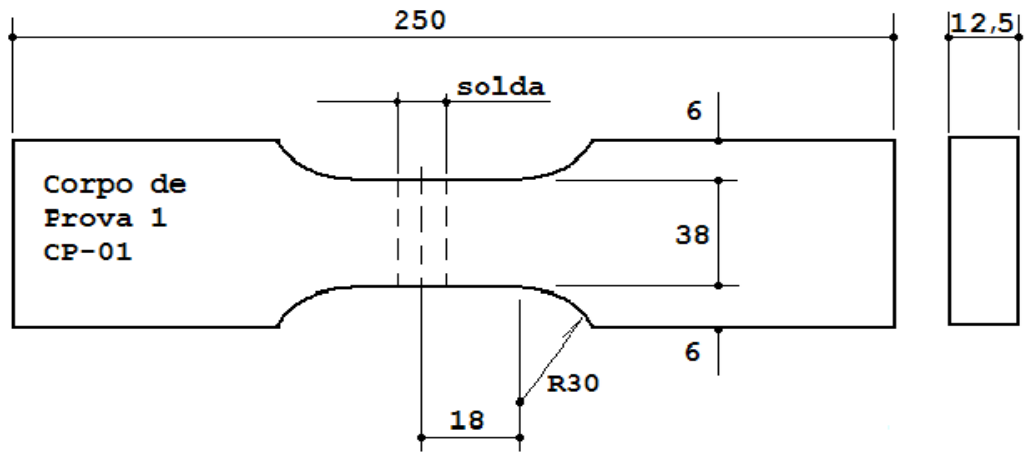

Figura 2. Dimensões dos CPs de tração.

\subsection{Parâmetros de Soldagem}

Os parâmetros de soldagem dos corpos de prova pelo processo MAG (GMAW) em ambos os corpos de prova foram: tensão de $22 \mathrm{~V}$ e corrente contínua de $140 \mathrm{~A}$ com polaridade inversa. O gás empregado foi o "Arcal 21" $\left(21 \% \mathrm{CO}_{2}+79 \% \mathrm{Ar}\right.$, vazão de 20 lpm [3]. Como metal de adição empregou-se o arame AWS A 5.18. ER70S-6, diâmetro 1,2 mm (micro-arame) [6]. Os materiais dos corpos de prova são confeccionados com o Aço SAE J403 1020. A composição química típica dos materiais envolvidos é: 
- consumível: 0,06 a 0,15\%C; 0,80 a 1,15\%Si; 1,40 a 1,85\%Mn.

- metal base: $0,20 \% \mathrm{C} ; 0,45 \% \mathrm{Mn} ; 0,20 \% \mathrm{Si} ; \mathrm{P} \leq 0,030 \%$ e $\mathrm{S} \leq 0,050 \%$.

A pistola para soldagem GMAW possui um contato elétrico deslizante (bico de contato) para transmitir a corrente ao arame, orifícios para a passagem de gás de proteção e bocal para dirigir o fluxo de gás à região do arco e da poça de fusão. Para a soldagem semi-automática, ela ainda possui um interruptor para o acionamento da corrente de soldagem, da alimentação de arame e do fluxo de gás de proteção. O sistema de alimentação do consumível (arame) é composto de um motor, um sistema de controle de sua velocidade e um conjunto de roletes responsável pela impulsão do arame.

\subsection{Procedimento de Soldagem}

Efetuou-se a soldagem dos corpos de prova e a elaboração do procedimento de soldagem, atendendo-se os requisitos da Norma ASME SEÇÃO IX (anexo 01). Antes da soldagem, os corpos de prova foram preparados com thinner para limpeza. A sequência realizada foi a seguinte: $1^{\circ}$ lado (superior): um passe de raiz, um passe de enchimento e um de acabamento. $2^{\circ}$ lado (inferior): um passe de acabamento, conforme ilustrado pela Figura 3.

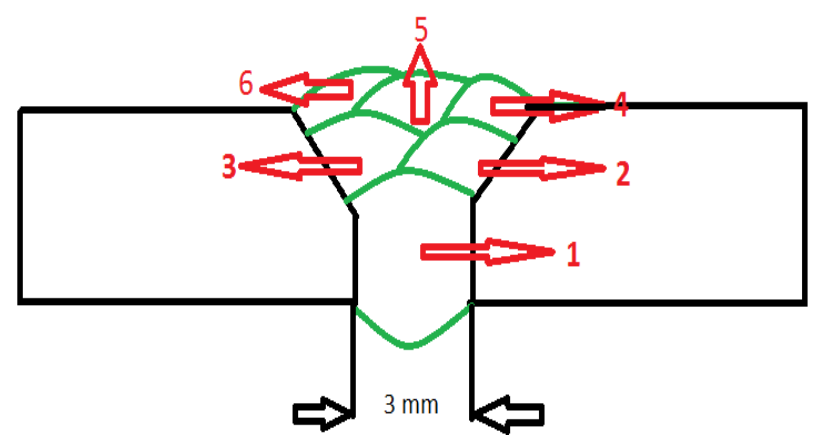

Figura 3. Esquema de passes de solda empregados no estudo.

\subsection{Ensaio de Tração}

Foi adotada a norma ASTM E8M [8] para realizar os ensaios mecânicos de tração, porém com as dimensões dos CPs conforme ASME. O ensaio foi realizado a temperatura ambiente e foram determinados o limite de escoamento, o limite de ruptura, o alongamento e a estricção do material. Empregou-se uma máquina universal hidráulica com capacidade de carga de 100 toneladas.
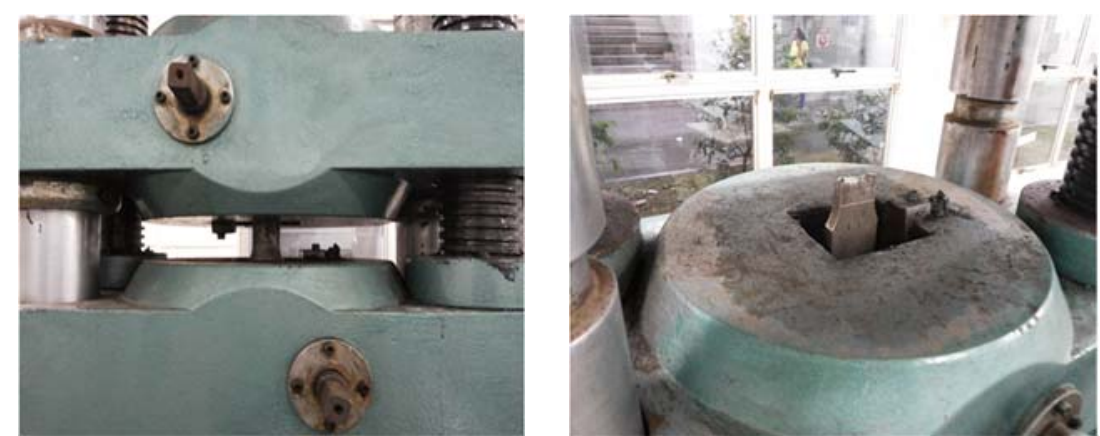

Figura 4. Fixação do CP à máquina de tração e exemplo de CP rompido. 


\subsection{Ensaios Metalográficos e Macrográficos}

A metalografia visa analisar e registrar a condição microestrutural de um material metálico através da preparação adequadas de amostras a serem observadas. Neste trabalho foi empregada esta técnica, na qual as amostras tiveram suas superfícies devidamente polidas e atacadas com um reagente específico. $O$ exame metalográfico encara o metal sobe o ponto de vista de sua estrutura, procurando relaciona-las às propriedades físicas, composição, processo de fabricação, etc. $[2,4,7]$

A Técnica do preparo de um dos corpo de prova de macrografia abrange as seguintes etapas [2]: escolha e localização da seção a ser estudada ,preparação de uma superfície plana e polida e ataque dessa superfície por um reagente químico adequado. Iniciando o lixamento nas lixas de 80, 100, 220, 320, 400 e 600 . polimento em politrizes com feltro de alumina $0,5 \mu \mathrm{m}$ e posterior ataque com reagente Nital a $5 \%$ para análise macrográfica e Nital a $2 \%$ para análise metalográfica. As análises foram feitas a nível macroscópico (a olho nu) e microscópico, com auxílio de um microscópio metalográfico da marca Olympus. Empregaram-se ampliações óticas de 50 a 1000X neste último caso.

\subsection{Ensaios de Dureza}

Pode-se considerar dureza como a resistência que um material oferece à penetração de outro em sua superfície. O ensaio de dureza pode ser feito em peças acabadas, deixando apenas uma pequena marca, às vezes quase imperceptível. No trabalho foram empregados os ensaios de dureza na escala Rockwell B (HRB), de acordo com a norma ASTM E 18, utilizando penetrador de esfera de aço temperado com 1/16" de diâmetro e 100 kgf de carga. A Figura 5 ilustra o equipamento da UNISANTA e as posições de medição de dureza realizados na junta soldada.
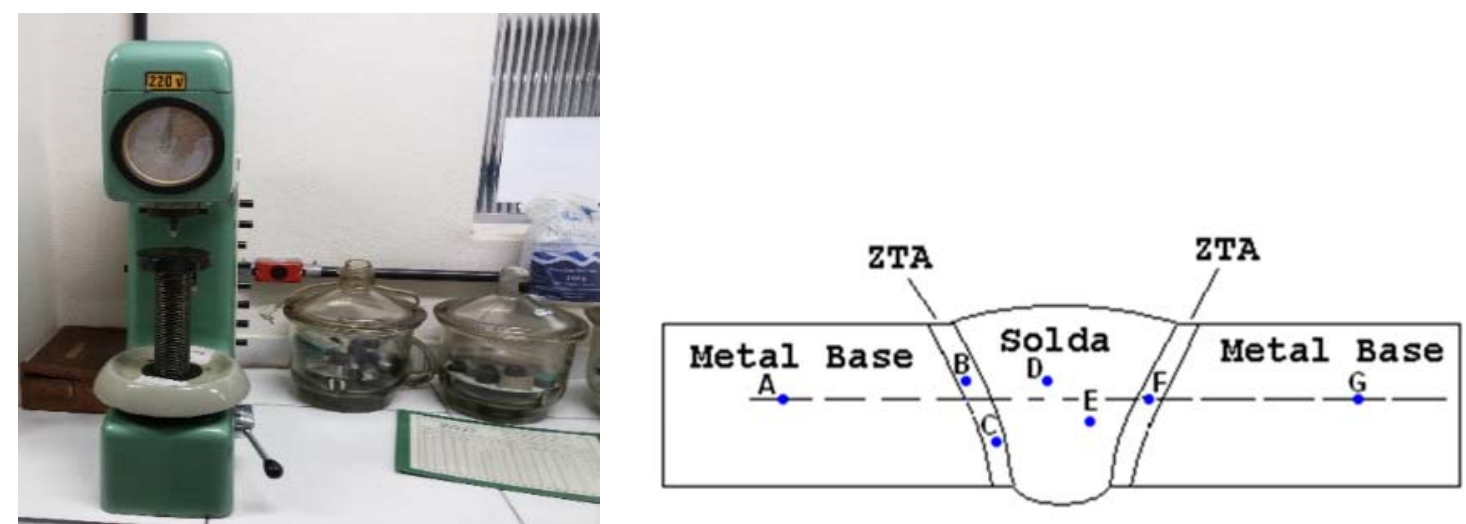

Figura 5. Durômetro laboratório UNISANTA (à esquerda) e posições das medições da dureza (à direita).

\section{RESULTADOS E DISCUSSÃO}

Após a soldagem observou-se que não houve deformação, que caracteriza bom procedimento e execução. Porém os resultados das demais avaliações devem ser consideradas para caracterizar mais fidedignamente o desempenho de junta. 


\subsection{Ensaio de Tração}

Os dados obtidos nos ensaios de tração foram: comprimento inicial $L_{0}=36,0 \mathrm{~mm}$; comprimento final $L_{F}=43,0 \mathrm{~mm}$; espessura inicial $t_{0}=12,5 \mathrm{~mm}$; espessura final (na região de ruptura) $t_{f}=11,0 \mathrm{~mm}$; largura inicial $B_{0}=38,0 \mathrm{~mm}$; largura final (na região de ruptura) $B_{F}=35,5 \mathrm{~mm}$ (Eq. 4); área inicial $A_{0}=475,0 \mathrm{~mm}^{2}$; área final $A_{f}=390,5$ $\mathrm{mm}^{2}$; força de escoamento $F_{E}=10280 \mathrm{kgf}$; força de ruptura $F_{R}=20460 \mathrm{kgf}$. Estes dois últimos valores foram registrados pelo controle eletrônico da máquina, conforme ilustrado na Figura 6. A Figura 7 ilustra o aspecto do CP de tração (vide Figura 1), rompido o ensaio de tração.
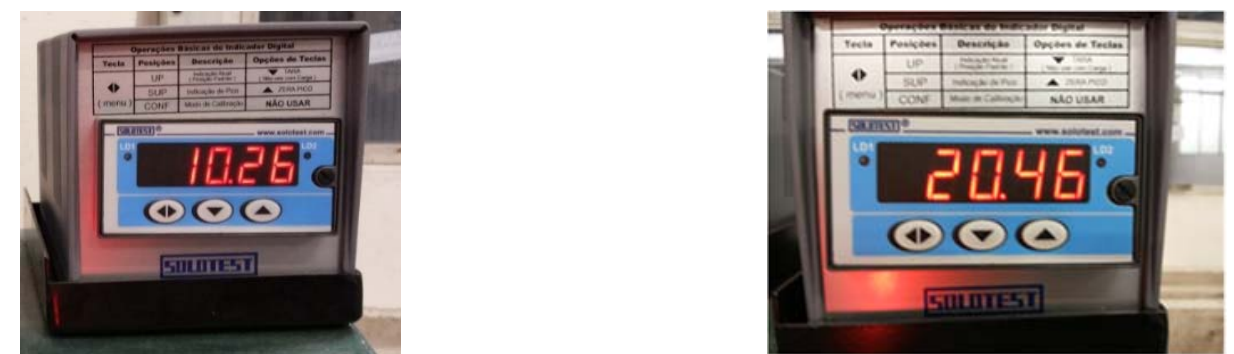

Figura 6. Registro das cargas de escoamento (à esquerda) e máxima (à direita).

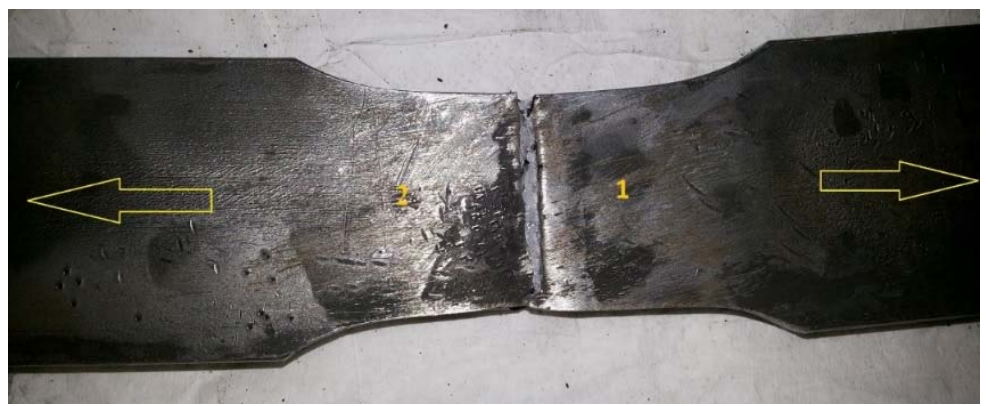

Figura 7. Aspecto do CP de tração rompido.

Os resultados numéricos, calculados a partir dos dados obtidos nos ensaios de tração, foram:

a) Limite de Escoamento (SLE)

$L E=\frac{F E}{A_{0}}=\frac{10260 \mathrm{kgf}}{475,0 \mathrm{~mm}} \times 9,81 \mathrm{~N}=211,89 \mathrm{Mpa}$

b) Limite de Ruptura ( $\mathrm{S}_{\mathrm{LR}}$ )

$L R=\frac{F R}{A_{0}}=\frac{20460 \mathrm{kgf}}{475,0 \mathrm{~mm}} \times 9,81 \mathrm{~N}=422,55 \mathrm{MPa}$

c) Alongamento (\%Along.)

$A l=\frac{L_{f}-L_{0}}{L_{0}}=\frac{43,0 \mathrm{~mm}-36,0 \mathrm{~mm}}{36,0 \mathrm{~mm}} \times 100=19,44 \%$

(Eq.3) 
d) Estricção ou Redução de Área (\%RA)

$e=\frac{A f-A_{0}}{A_{0}}=\frac{390,5-475,0}{475,0} \times 100=-17,79 \%$

As superfícies de fratura obtidas nos ensaios de tração foram avaliadas para determinar a existência de irregularidades, descontinuidades e/ou defeitos. A foto da Figura 8 apresenta regiões de falta de fusão ocorridas entre os passes de solda executados (vide Figura 3).

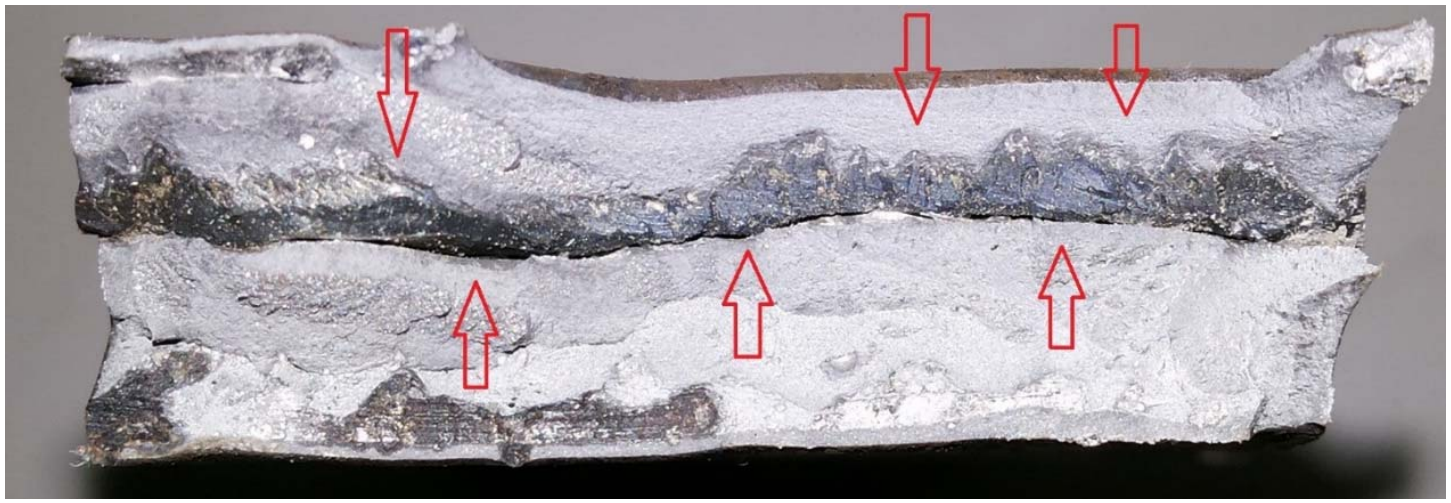

Figura 8. Vista da seção transversal da fratura obtida após o ensaio de tração.

\subsection{Macrografia e Micrografia}

Apresentou uma estrutura bem homogênea, conforme ilustrado pela Figura 9, podendo definir o metal de adição, o metal base, e verificado a presença da zona termicamente afetada (ZTA). Verificou-se também que não foi verificada uma falta de fusão na solda deste corpo de solda na região cortada, ao contrário do percebido na superfície de fratura do CP de tração.

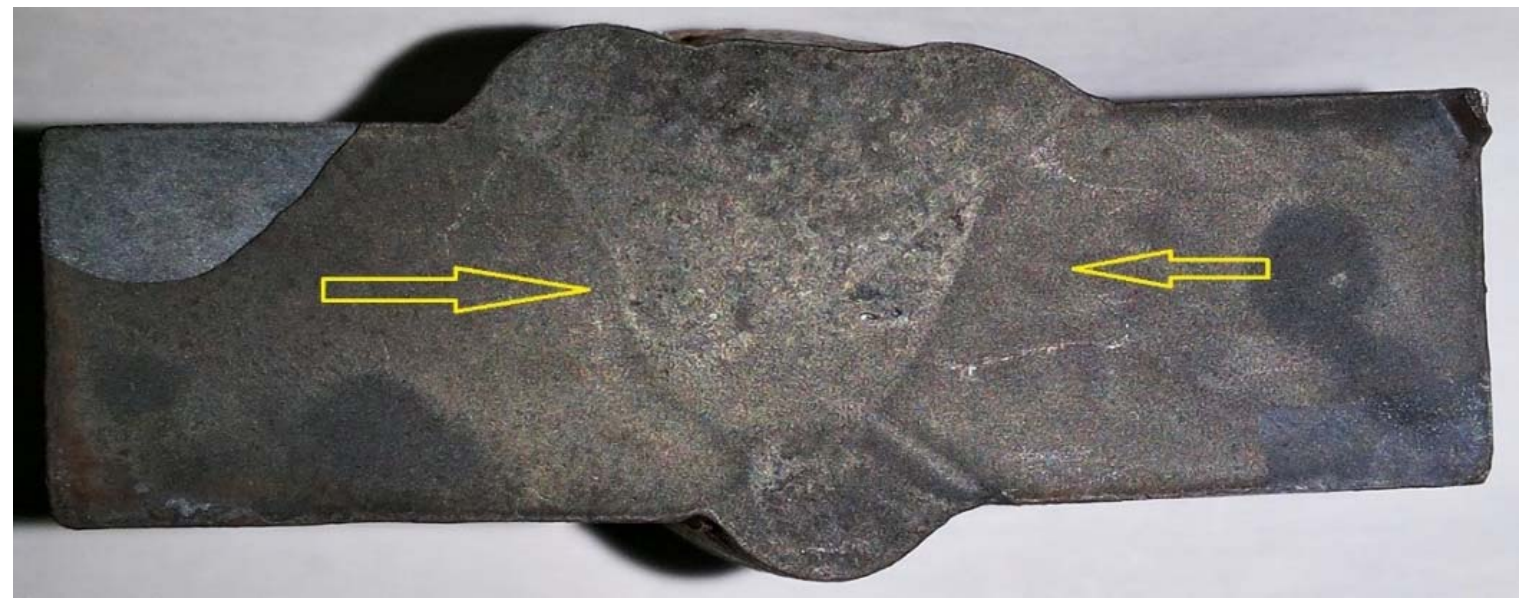

Figura 9. Registro macrográfico da junta soldada empregada neste estudo.

Através da metalografia, pode-se observar alinhamento da perlita (bandeamento) na região do metal base conforme ilustrado na Figura 10. Este bandeamento é típico de chapas de aço obtidas por laminação a quente. Já a Figura 11 apresenta a estrutura do metal de solda, com o aspecto típico para o consumível empregado (AWS A 5.18. ER70S-6). 

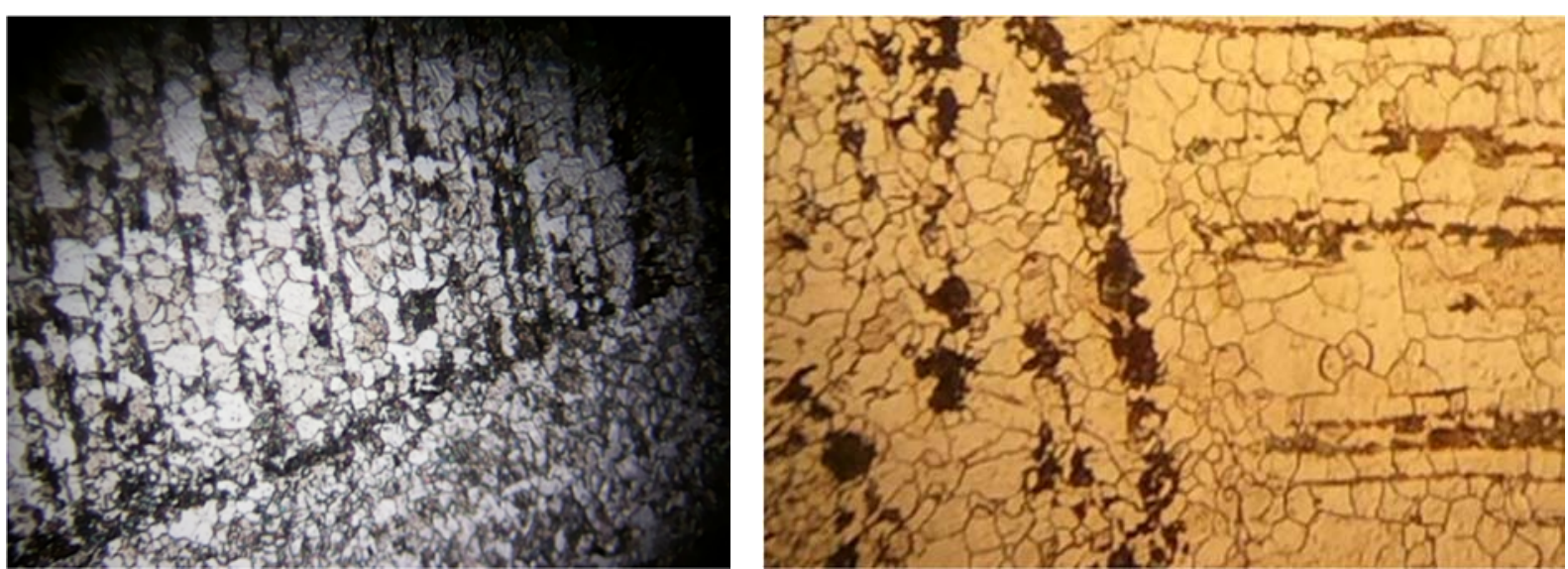

Figura 10. Aspecto metalográfico do metal base, próximo à ZTA (ataque: Nital a $2 \%$ e ampliação ótica de 50X).

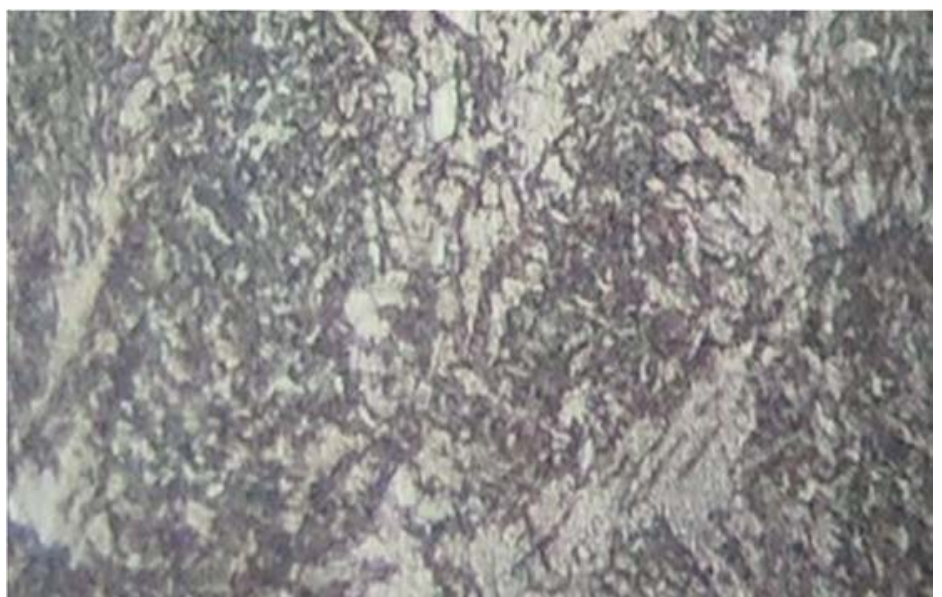

Figura 11. Aspecto metalográfico do metal depositado por solda.

\subsection{Dureza}

Os ensaios de dureza foram executados nas regiões planejadas (vide Figura 5) conforme ilustrado na Figura 12. Os resultados obtidos estão apresentados no gráfico da Figura 13.

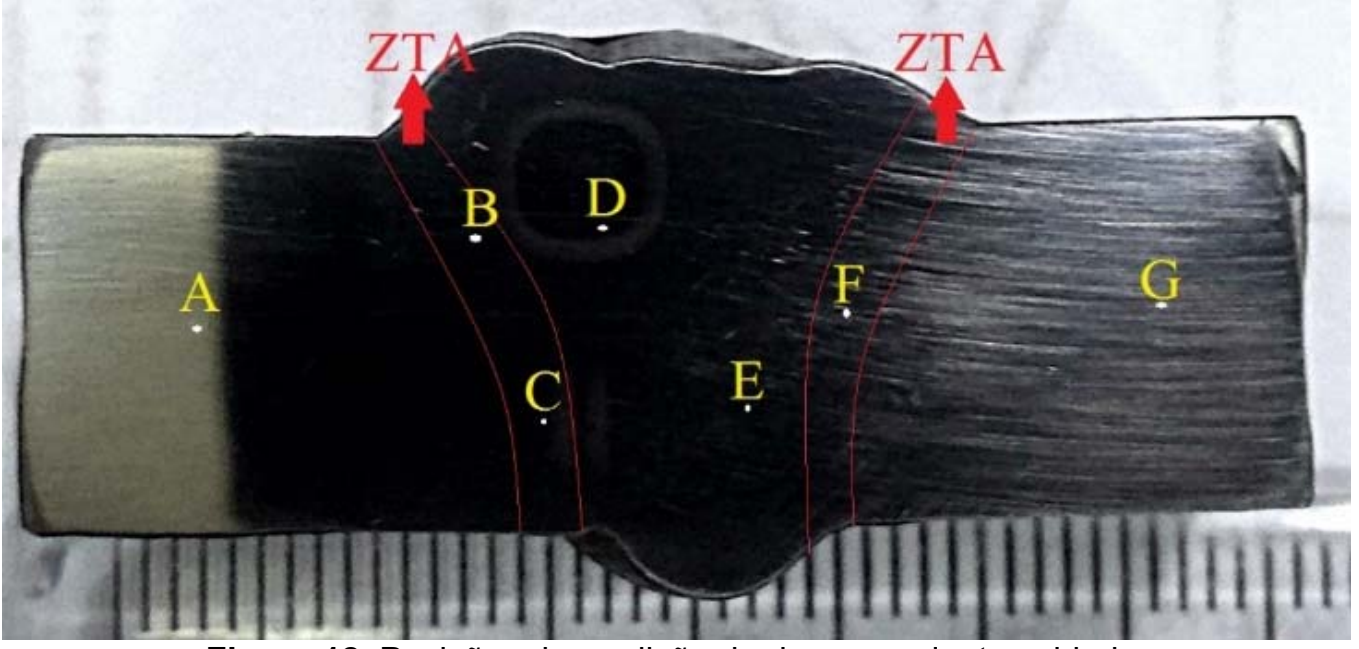

Figura 12. Posições de medição de dureza na junta soldada. 


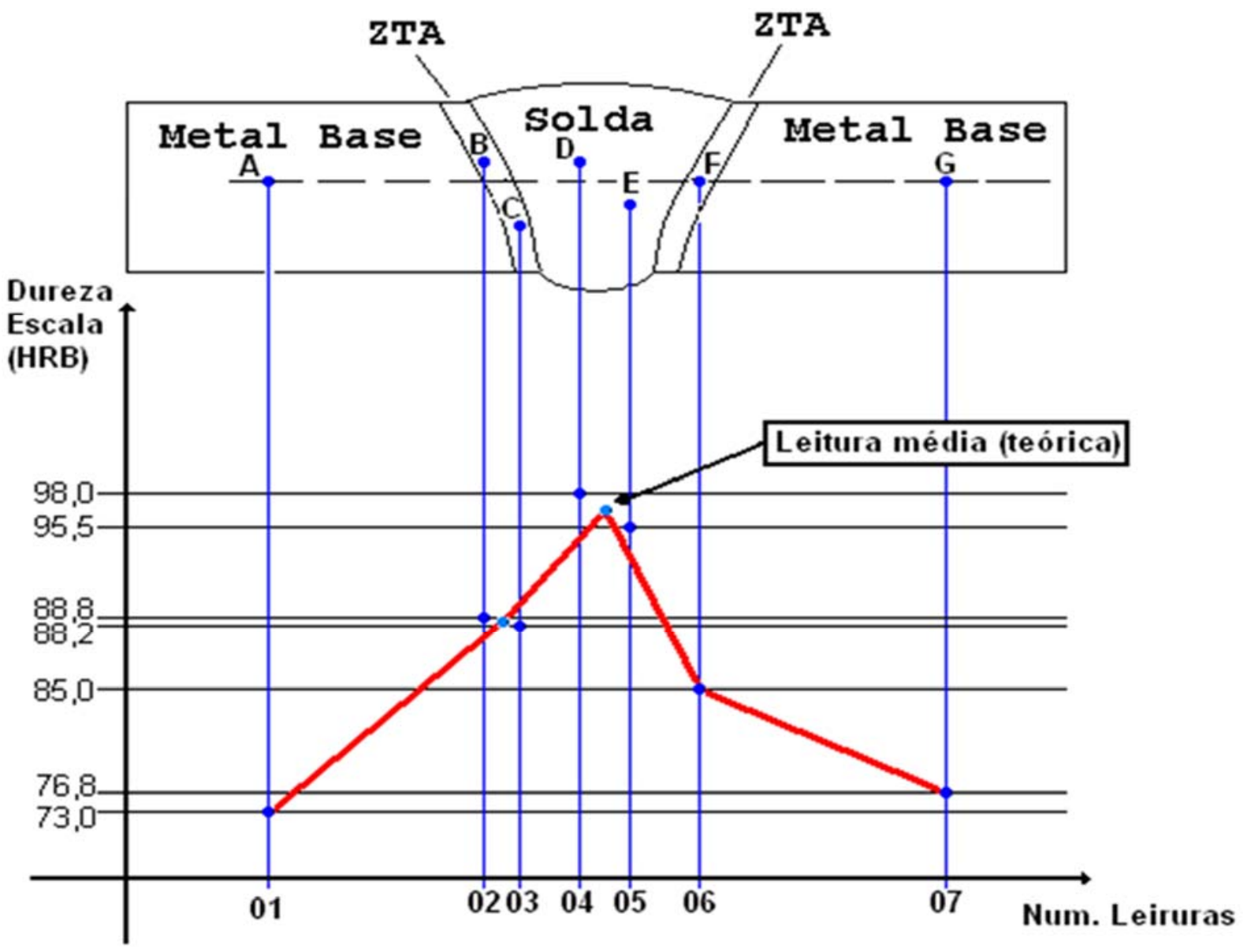

Figura 13. Resultados da solda.

Valores mais elevados de dureza registrados na região da solda, tanto no metal de solda quanto na ZTA, não são favoráveis para o desempenho mecânico da junta. Entretanto, os valores obtidos desse ensaio, apesar de mais elevados no metal de solda, ainda estão dentro de um nível satisfatório.

\section{CONCLUSÃO}

A soldagem é um método de união localizada de materiais, cujo objetivo básico é manter a continuidade das características da união com o restante do componente. Através do trabalho aqui apresentado, podemos concluir que o processo propriamente dito de soldagem, material adequado, temperatura não é o suficiente para garantir uma junção de qualidade, justificando, portanto, a qualificação de soldador e do procedimento de soldagem, fazendo-se necessário o treinamento de todo o pessoal de execução e planejamento do trabalho.

Os resultados do ensaio de tração comprovam que a inabilidade do soldador influenciou significativamente para a sanidade da solda e que se esta fosse exposta há uma solicitação real, correria o risco de comprometer o objetivo da soldagem. As avaliação visual da junta soldada, as análises metalográfica e por dureza não indicaram maiores irregularidades. Os ensaios mecânicos destrutivos, no caso o ensaio de tração, são mais indicados para uma avaliação mais precisa de uma junta soldada pois defeitos não perceptíveis por outras técnicas podem manifestar-se na superfície de fratura final obtida. 


\section{REFERÊNCIAS}

1 Morais, W. A.; Magnabosco, A. S; Netto, E. B. M. Metalurgia física e mecânica aplicada. 2. ed. São Paulo: ABM, 2009.

2 Colpaert. H, "Metalografia dos Produtos Siderúrgicos Comuns", Ed. Edgard Blucher

3 Arcal $^{\mathrm{TM}} 5$ Smartop/Arcal ${ }^{\mathrm{TM}} 12$ Smartop/Arcal ${ }^{\mathrm{TM}} 21$. Acesso em 18 set 2014. <http://www.airliquide.pt/file/otherelement/pj/50/ac/c6/0f/arcal\%E2\%84\%A221\%20smart op\%20(300-15-014pt)6260696717045058782.pdf>.

4 Van Vlack. Lawrence H, Princípios de Ciência dos Materiais. 4.ed. Bluecher Ltda.

5 Infosolda, < http://www.infosolda.com.br.> Acesso em 18 set 2014.

6 ESAB MIG Welding Handbook - ESAB Welding \& Cutting Products

7 Matweb Material Proprety Data. Acesso em 26 ago 2014. Disponível em: $<$ http://www.matweb.com/search/DataSheet.aspx?MatGUID=823fa22659bf41be98deffe d50d5e7e4>

8 Standard Test Methods for Tension Testing of Metallic Materials ASTM E8M < http://www.astm.org/Standards/E8.htm > Acesso em 26 ago 2014. 